\section{Representações de professores sobre ensino remoto na transição das aulas presenciais às remotas on-line}

Teacher representations about remote teaching in the transition from face-to-face classes to online remotes

Paulo Ricardo Ferreira PEREIRA (UFCG) ricardo.ferreira@estudante.ufcg.edu.br Denise LINO DE ARAÚJO (UFCG) denise.lino@professor.ufcg.edu.br

Recebido em: 31 de jan. de 2021. Aceito em: 25 de ago. de 2021.
PEREIRA, Paulo Ricardo Ferreira; LINO DE ARAÚJO, Denise. Representações de professores sobre ensino remoto na transição das aulas presenciais às remotas on-line. Entrepalavras, Fortaleza, v. 11, n. 3, e2265, p. 233-254, set.-dez./2021. DOI: 10.22168/22376321-32265.

Resumo: Este trabalho justifica-se por apresentar o ofício do professor em contexto de distanciamento social, dada a pandemia sanitária decorrente da COVID-19 que instaurou crises em diversas instituições sociais. Motivados pelo questionamento - Que crises parecem se sobrepor nos relatos de professores em situação de pandemia? - propomos-nos a investigar representações de professores sobreensino remoto no cenário de transição das aulas presenciais às remotas on-line. Especificamente, reconhecemos como objetivos: i) identificar representação(ões) de professores sobre ensino remoto em contexto de distanciamento social; ii) verificar recepção de professores sobre a implantação do ensino remoto no cenário de transição do ensino presencial ao on-line. Teoricamente, partimos de considerações sobre educação mediada por tecnologias digitais, ensino remoto, letramento digital, representações sociais e profissionais. Metodologicamente, este estudo se insere no paradigma qualitativo com abordagem netnográfica. Os dados foram gerados através de formulário online e de sessões com grupo focal online. Para amostragem, elegemos o corpus desenvolvido na primeira sessão com um professor de Português e um professor de 
V. 11 (3)

233-254

set-dez

2021

Biologia. Ao identificarmos que os participantes compreendem o ensino remoto como uma medida emergencial, verificamos que a transição das aulas não ocorreu de forma pacífica, pois foram surpreendidos pela implantação e não se sentem representados pelas intervenções governamentais. Os dados parecem indiciar uma crise instaurada na condição de atuação da classe, visto que há uma sobreposição de barreiras opacas entre as ações profissionais e familiares. O ambiente antes familiar é "invadido" pelo espaço profissional, constituindo um espaço de desterritorialização/reterritorialização que implica nas práticas educacionais.

Palavras-chave: Professor em distanciamento social. Representações Profissionais. Ensino Remoto.

Abstract: This work is justified by presenting the teacher's office in a context of social distancing, given the health pandemic resulting from COVID-19 that initiated crises in several social institutions. Motivated by questioning - What crises seem to overlap with the reports of teachers in pandemic situations? - we propose to investigate representations of teachers about remote teaching in the transition scenario from face-to-face to remote online classes. Specifically, we recognize as objectives: i) to identify representation(s) of teachers about remote teaching in a context of social distancing; ii) verify reception of teachers about the implementation of remote education in the transition scenario from face-to-face to online teaching. Theoretically, we start from considerations about education mediated by digital technologies, remote teaching, digital literacy, social and professional representations. Methodologically, this study is part of the qualitative paradigm with a netnographic approach. The data were generated through an online form and online focus group sessions. For sampling, we elect the corpus developed in the first session with a teacher Portuguese and a Biology teacher. By identifying that the participants understand remote education as an emergency measure, we found that the transition of the classes did not occur peacefully, because they were surprised by the implementation and did not feel represented by government interventions. The data seem to indicate a crisis established in the condition of the class's performance, since there is an overlap of opaque barriers between professional and family actions. The previously familiar environment is "invaded" by the professional space, constituting a space of deterritorialization/reterritorialization that implies in educational practices.

Keywords: Teacher in social distancing. Professional Representations. Remote Teaching.

\section{Introdução}

A COVID-19 (Sars-CoV-2) foi qualificada pela Organização Mundial de Saúde (OMS), em 11 de março de 2020, como causadora de uma pandemia, pois instaurou uma crise sanitária que impactou globalmente a vida em sociedade. A rápida propagação desse vírus acentuou o uso das tecnologias digitais, tornando-as primordiais para o estabelecimento de um vínculo mínimo para as relações humanas e os laços de pertencimento, dado que uma das medidas para atenuar sua disseminação é o distanciamento social entre as pessoas. Em função desse contexto pandêmico, o que era visto como um recurso de caráter complementar se tornou essencial para a manutenção de práticas, ações e interações em diversos ambientes profissionais, dentre eles, na instituição escolar (LINO DE ARAÚJO et al., 2020). 
No Brasil, em 13 de março de 2020, dias antes do pronunciamento de entidades educacionais, como do Ministério da Educação (MEC) e do Todos Pela Educação (TPE), escolas públicas e particulares sinalizaram o fechamento generalizado como uma maneira de dificultar a propagação do vírus, que demonstrou crescimento alarmante nos estados do Rio de Janeiro e de São Paulo. A paralisação total foi efetivada na sequência, sendo reconhecida oficialmente no dia 17 de março ${ }^{1}$, e fortalecida com a campanha televisiva e digital \#FiqueEmCasa, lançada ainda em março, o que promoveu a política de isolamento e distanciamento social.

Esse cenário desencadeou uma série de ações por parte de setores, representantes e atores profissionais do campo educacional. Em 27 de abril de 2020, em caráter emergencial, alguns representantes dos estados e municípios brasileiros recomendaram a transição das aulas presenciais às aulas on-line para a Educação Básica, de modo a garantir não só a continuidade dos conteúdos e saberes trabalhados até aquele momento, mas também o vínculo interacional que marca a relação entre a escola e seus atores (gestores, professores, alunos, pais/ responsáveis etc.).

Foi nesse contexto pandêmico que as reflexões sobre ensino remoto (síncrono e assíncrono) chegaram ao Brasil. Nessa interface, tanto os professores como os alunos foram surpreendidos pela transição das aulas presenciais às remotas on-line por meio de plataformas digitais (Google Classroom, WhatsApp, Google Meet e Zoom, dentre outras), o que impulsionou problematizações, a exemplo das condições materiais, físicas e psicológicas de alunos e professores em meio à transição desse processo de ensino-aprendizagem presencial ao virtual.

As discussões, especificamente, problematizaram desde a ruptura de representações, expectativas e certezas até a inserção desses atores educacionais à interface digital, visto a desigualdade que dificulta não só o acesso à internet, mas a própria movimentação dos sujeitos nesse ambiente, i.e., a ausência de letramento digital. Em outras palavras, esse contexto excepcional acentuou crises em diversos setores das instituições sociais (saúde, economia, educação, política) e nos sujeitos que as compõem.

\footnotetext{
${ }^{1}$ Em 18 de março, o MEC publicou nota sobre a situação da educação brasileira nesse contexto pandêmico. Na Portaria no 343, de 17 de março de 2020, o (até então) ministro Abraham Weintraub legitimou a necessidade da utilização de tecnologias de informação e comunicação digitais como uma forma de minimizar os impactos decorrentes da COVID-19 nas instituições de Ensino Superior, mas reconhecendo os limites da substituição.
} 
V. 11 (3)

233-254 set-dez

2021

Diante dessa conjuntura socioeducacional, e por compreendermos que esse campo está permeado por crises de diferentes ordens (TARDIF; LESSARD, 2014), particularmente, focalizamos as reflexões sobre professores em atividade ao questionarmos: Que crises parecem se sobrepor nos relatos de professores em situação de pandemia? Para respondermos a esse questionamento, reconhecemos como objetivos: i) identificar representação(ões) de professores sobre ensino remoto em contexto de distanciamento social; ii) verificar recepção de professores sobre a implantação do ensino remoto no cenário de transição do ensino presencial ao on-line. Os dados deste estudo fazem parte de uma pesquisa mais ampla de dissertação de mestrado (em andamento)² e constituem a exploração de indícios analíticos.

A pesquisa ora apresentada justifica-se por documentar esta crise decorrente da COVID-19 através da perspectiva do professor em atuação na Educação Básica. O grupo focal on-line (MURRAY, 1997) passou a constituir um local de escuta entre "pares", destinado a fomentar a visão desses profissionais, bem como possibilitou reflexões profícuas para a formação dos colaboradores. Além de contribuir com reflexões teóricas sobre ensino remoto no campo de investigação da Linguística Aplicada indisciplinar (MOITA LOPES, 2006; 2013), este estudo possui caráter colaborativo, que, segundo Miller (2013), envolve uma reflexividade de mão dupla, pois os resultados alcançados auxiliam não só o pesquisador, mas também os participantes. É nesse sentido que ressaltamos a retroalimentação dos dados alcançados, uma vez que os resultados obtidos retornarão aos participantes que demonstraram interesse em verificá-los.

Na seção seguinte a esta introdução, apresentamos brevemente o arcabouço teórico sobre educação mediada por tecnologias digitais, de modo a evidenciar a condição de ensino remoto e o conceito de letramento digital, e a Teoria das Representações Sociais como propulsora das Representações Profissionais. Após essa explanação, expomos os procedimentos metodológicos que embasaram esta pesquisa. Em sequência, analisamos as representações profissionais sobre ensino remoto a partir do que foi verificado nas contribuições dos professores à luz dos pressupostos teórico-metodológicos eleitos. Por fim, tecemos as considerações finais.

\footnotetext{
${ }^{2}$ A pesquisa 0 professor leitor da Base Nacional Comum Curricular: recepção e representações foi submetida à Plataforma Brasil, em 18 de fevereiro de 2020, para fins de apreciação ética por parte do Comitê de Pesquisa. O parecer de aprovação pode ser conferido através do Certificado de Apresentação para Aprovação Ética (CAEE) de número 29680220.2.0000.5182.
} 


\section{Considerações sobre educação mediada por tecnologias digitais, ensino remoto e letramento digital}

Na esfera escolar, a performance dos atores educacionais, notadamente professores e alunos, incorpora artifícios da cultura digital para além da mera utilização em sala de aula, dada a sua função crítica e socializadora. Nessa perspectiva, entendemos que a inserção e o uso de artefatos tecnológico-digitais implicam na gênese educacional, visto que, como avalia Lévy (1999, p. 31), "as tecnologias digitais surgiram, então, como a infraestrutura do ciberespaço, novo espaço de comunicação, de sociabilidade, de organização e de transação" e, de igual modo, "[...] novo mercado da informação e do conhecimento."

Decorrente desse cenário de nova produção e circulação de conhecimento, a instituição escolar é vista como determinante para a inserção e legitimação dos sujeitos à cultura digital. Gama (2012), por exemplo, entende a escola como a principal agência de fomento de práticas letradas digitalmente. Em suas palavras, é atribuído à instituição escolar "contextualizar seu ensino à atualidade, levar também em conta as alterações culturais advindas da utilização diária das TDICs fora do âmbito escolar e inseri-las", considerando "termos materiais (laboratórios de informática, computadores com internet etc.) e humanos (formação de professores, conscientização de alunos)." (GAMA, 2012, p. 8).

Ao avaliar o uso de abordagens tecnológicas na educação, Xavier (2005, p. 3) reconhece uma mudança de perfil de professor e aluno. Espera-se do primeiro um profissional pesquisador, articulador de saberes, gestor de aprendizagens, consultor e motivador de uma aprendizagem fundamentada nas acepções de "descoberta" e "investigação". Em face disso, o segundo passa a ser reconhecido como um sujeito ativo, o que envolve considerar sua(s) independência, autonomia, necessidades e seus tópicos de interesse, para que desenvolva habilidades e competências demandas pelo contexto em que transita enquanto sujeito social (LINO DE ARAÚJO et al., 2020).

Na condição de ensino remoto, no entanto, observamos que parece prevalecer uma tendência de transferir ações e práticas geralmente realizadas no contexto de ensino presencial. Dias-Trindade, Correia e Henriques (2020, p. 6) reforçam essa visão, quando ressaltam que essa modalidade "resulta, pois, de uma resposta imediata a uma crise, concretamente a provocada pela pandemia COVID-19, com o objetivo 
V. 11 (3)

233-254

set-dez

2021

de manter as atividades letivas" e, por conta disso, "traduz-se numa mudança rápida dos processos de ensino e aprendizagem presenciais para modelos alternativos, tecnologicamente mediados."

Sob esse ângulo, o domínio de práticas letradas digitais, por parte de professores e alunos, pode ser concebido como uma necessidade educacional e de sobrevivência social (XAVIER, 2005). Do ponto de vista conceitual, o termo letramento digital assume diversas acepções, que o compreendem como tipo, paradigma, modalidade etc. Neste estudo, partilhamos da compreensão de Martin (2008), para o qual letramento digital se refere:

[...] à consciência, atitude e habilidade dos indivíduos de apropriadamente usarem ferramentas digitais e instalações para identificar, acessar, gerenciar, integrar, avaliar, analisar e sintetizar recursos digitais, construir novos conhecimentos, criar expressões midiáticas e comunicar aos outros, no contexto específico das situações da vida, a fim de possibilitar uma ação social construtiva; e para refletir sobre esse processo. (MARTIN, 2008, p. 167).

A conceituação proposta por Martin (2008) pressupõe uma consciência crítica que possibilita ao sujeito social, enquanto usuário e integrante da rede mundial da internet, não só realizar ações, mas também modificar e refletir sobre no próprio contexto digital. Em outras palavras, esse sujeito não é apenas mais um usuário passivo, mas um integrante do grande sistema computacional, ou seja, alguém que, ao fazer parte, o modifica significativamente, através de ações (in)conscientes, a fim de atender às necessidades demandadas pelo contexto em que ele está ocupando. Tal entendimento permite nos associarmos, neste estudo, à acepção auto-heteroecoformação tecnológica de Freire e Leffa (2013), para os quais a relação entre as práticas e os sujeitos corresponde à:

Ação do meio ambiente - presencial e/ou digital — sobre os indivíduos, mediada por ferramentas, práticas e linguagens singulares, aliada a uma ação crítico-reflexiva desses indivíduos sobre o meio, sobre os outros e sobre si mesmos, apropriandose dessas ferramentas, práticas e linguagens, para usá-las, de maneira pertinente e adequada, na construção/desconstrução/ reconstrução do conhecimento e na sua inserção crítica nos mundos presencial e digital [...]. (FREIRE; LEFFA, 2013, p. 75, grifo dos autores).

Associado a esse quadro de educação mediada por tecnologias e domínio de práticas letradas digitais, o conceito de ensino remoto surge, no Brasil, enquanto uma representação emergente sob o viés social e 
profissional em um contexto marcado pela incerteza e pela fragilidade decorrentes das consequências da pandemia de COVID-19. Na seção a seguir, sistematizamos os pressupostos das representações sociais da vertente moscoviciana e introduzimos as bases das representações profissionais.

\section{Das representações sociais às representações profissionais}

As relações e instituições sociais são constituídas e mediadas por dimensões representativas que decorrem de estruturas socioculturais e históricas, cuja centralização demarca a nossa forma de agir e interagir nas esferas que constituem o cotidiano. Para Guareschi e Jovchelovitch (1995, p. 20), as dimensões representativas são evidenciadas e formadas "[...] quando as pessoas se encontram para falar, argumentar, discutir o cotidiano, ou quando elas estão expostas às instituições, aos meios de comunicação, aos mitos e à herança histórico-cultural [...]." Os processos que moldam e estruturam a vida em sociedade são investigados, entre outros, pela Teoria das Representações Sociais (doravante TRS), principalmente quando as representações entram em um movimento de instabilidade/ruptura, tal qual o contexto instaurado pela pandemia da COVID-19.

A TRS, empreendida inicialmente por Serge Moscovici, em 1961, é compreendida como um construto teórico-metodológico constituído por representações qualificadas como dinâmicas e complexas. Moscovici (2007) as caracteriza como um conjunto constituído por determinadas questões (crenças, valores, experiências etc.) que convencionam e prescrevem artefatos, objetos, pessoas e acontecimentos. Do ponto de vista operacional, a TRS permite o desvelamento das simbologias sociais a partir da articulação de dois princípios intimamente associados: ancoragem, que é quando nos deparamos com algo que nos causa estranhamento/perturbação e o comparamos com uma categoria que julgamos ser adequada, ou seja, classificamos, positiva ou negativamente, e atribuímos nomes a alguma coisa, reduzindo-a a categorias e imagens comuns; objetivação, por meio do qual reproduzimos um conceito em uma imagem, concretizando-o (MOSCOVICI, 2007).

Com base nesse reconhecimento operacional, Moscovici (2007, p. 54) avalia que a finalidade da TRS "[...] é tomar [sic] familiar algo não-familiar, ou a própria não-familiaridade." Em outras palavras, o quadro teórico-metodológico e analítico desse campo epistemológico 
V. 11 (3)

233-254

set-dez

2021

pressupõe um processo de desvelamento interno (psico-cognitivo) e externo (social) da realidade que circunda os homens, a fim de compreendê-la sob um ângulo interpretativo.

Ao contribuir com essa vertente moscoviciana, Jodelet (2001, p. 22) entende representação social como "forma de conhecimento, socialmente elaborada e partilhada, com um objetivo prático, e que contribui para a construção de uma realidade comum a um conjunto social." Esse entendimento reafirma as representações sociais como fenômenos complexos que impactam na vida em sociedade, pois dizem algo sobre a realidade que estamos vivenciando e, por isso, estão em um processo espontâneo de impermanência constante. Para essa autora, essas representações intervêm - organizam, orientam, condicionam, prescrevem etc. - em processos variados, a exemplo da produção, difusão e assimilação de conhecimentos, do desenvolvimento individual e coletivo, da definição de identidades (pessoais, sociais, profissionais etc.), da manifestação de grupos e transformações sociais, além da exteriorização e da (re)construção de saberes socialmente constituídos e partilhados (JODELET, 2001).

Sob esse ângulo, compreendemos que a TRS possibilita uma "ramificação" de representações identificadas como profissionais, porque, ao ver "[...] o ser humano enquanto ele tenta conhecer e compreender as coisas que o circundam [...]" (MOSCOVICI, 2007, p. 42), deparamos com o seu empreendimento em diferentes agências e espaços sociais, dentre eles, nos ambientes profissionais. Nesse sentido, reconhecemos que existe certa interdependência entre as representações sociais e as representações profissionais, por meio da qual os estados, as condutas, as simbologias e os processos representativos que estruturam atuações e espaços profissionais podem ser desvelados pela acepção de "representações profissionais".

Por representações profissionais, fundamentamos nas contribuições de Blin (1997, p. 80), para o qual são "[...] elaboradas na ação e na comunicação profissionais (interagir e inter-reagir)" e, por conta disso, "são especificadas pelos contextos, pelos atores pertencentes a grupos e pelos objetos pertinentes e úteis para o exercício das atividades profissionais." Abdalla (2017) entende que esse tipo de representação social se refere à atuação e aos papéis profissionais desenvolvidos em uma situação de interação específica, que está sendo vivenciada pelos sujeitos em dado momento, e que envolve características que movimentam o ambiente social e profissional. 
Esse entendimento das representações profissionais, ainda conforme Blin (1997), está fundamentado em três dimensões: funcional, contextual e identitária. Abdalla (2017, p. 177) sistematiza essas dimensões ressaltando que a primeira contempla objetos que são ativados na atuação profissional e os seus significados no exercício em curso; a segunda corresponde ao regimento dessa função, ou seja, à(s) organização, instituição, atividades, ideologias e aos papéis assumidos pelos sujeitos; e a terceira contempla motivações, competências laborais, projetos e idealização do ser profissional. Concordamos com a leitura de Alves (2016) sobre essas dimensões e compreendemos que as representações profissionais não são nem conhecimentos de caráter estritamente científico nem de senso comum, mas saberes circunscritos que são elaborados na ação e interação laborais sobre um objeto que faz parte da experiência e do cotidiano dos sujeitos profissionais, o que permite que eles reflitam sobre.

Essas considerações teóricas denotam o aparato teóricometodológico de ordem socioprofissional que configuram as representações profissionais, enquanto campo interdependente das representações sociais. É esse alinhamento teórico das representações sociais às profissionais que possibilita investigarmos representações de professores sobre ensino remoto no cenário de transição das aulas presenciais às remotas on-line. Compreendemos esse momento como propulsor de um ponto de instabilidade nas representações de professores sobre as simbologias das estruturas sociais, especificamente, sobre o processo de ensino-aprendizagem que se desvela na condição de ensino remoto. Na seção seguinte, expomos os procedimentos metodológicos eleitos para realização desta investigação.

\section{Grupo focal on-line como instrumento de obtenção de representações profissionais}

Este estudo se desenvolve sob o arcabouço do paradigma qualitativo de natureza descritivo-interpretativista (BORTONIRICARDO, 2008) e do quadro teórico-metodológico da abordagem netnográfica. Compreendemos essa abordagem, a partir de Kozinets (2014), como uma pesquisa de campo on-line de caráter observacional e participativo, que se propõe a investigar práticas, situações e interações específicas que são desenvolvidas em comunidades virtuais. Nessa perspectiva, esta pesquisa se qualifica como netnográfica "pura", visto 
V. 11 (3)

233-254 set-dez 2021

que todas as ações foram mediadas através do uso de computadores e celulares, assim como os dados foram extraídos e gerados por meio do contato virtual com a comunidade constituída.

Ao preconizar relações entre fenômeno de estudo, sujeito e mundo sob um ponto de vista integrativo, apoiamo-nos na Teoria da Complexidade (doravante TC) para analisarmos os dados indiciários sobre ensino remoto. A TC, enquanto tecida de constituintes heterogêneos e inseparavelmente associados, é compreendida por Morin (1990; 2005) como uma aspiração à complexidade, visto que tende para um conhecimento multidimensional através dos princípios de diálogo, recursão organizacional e hologramático. Por essa razão, não se propõe a ser unívoca e fornecer todas as informações sobre o objeto em estudo, mas respeitar as dimensões contextuais em que emergem as interpretações dos sujeitos envolvidos (MORIN, 2005).

Por considerarmos a linguagem um sistema complexo (LARSEN-FREEMAN, 2006), reconhecemos a Linguística Aplicada (LA) como um campo investigativo profícuo para o desenvolvimento deste estudo. A LA, ao lidar com o múltiplo e o complexo, configura-se como uma ciência de caráter social indisciplinar. Em linhas gerais, podemos entendê-la como uma ciência de produção de conhecimentos que não se limita às zonas disciplinares e aos princípios teórico-metodológicos e analíticos que constituem os campos investigativos (MOITA LOPES, 2015). Ao contrário, é uma acepção que instiga o diálogo com outros campos de saberes, face às demandas da pesquisa e às interfaces contextuais do objeto.

De posse desse quadro teórico-metodológico, investimos na técnica de grupo focal on-line como instrumento para obtermos representações profissionais por parte de professores, visto a possibilidade de ouvirmos vários sujeitos, ao mesmo tempo, refletindo sobre um tema em específico - ensino remoto -, de modo a visibilizarmos informações, sentimentos, experiências e representações do grupo (KIND, 2004). Murray (1997) entende que as sessões, com o grupo constituído, podem ser conduzidas de modo síncrono ou assíncrono. Para esse autor, a escolha da modalidade das sessões e da plataforma (chat on-line, e-mail, listas e fóruns de discussões etc.) depende da receptividade, da familiaridade e da disponibilidade dos participantes envolvidos no grupo.

Para constituição do grupo focal on-line, partimos dos apontamentos de Bordini e Sperb (2011), que ressaltam etapas e 
procedimentos para a constituição do grupo, quais sejam: mobilização dos participantes; escolha do programa/local de comunicação; construção do guia de discussão (temário); envio do termo de consentimento livre e esclarecido (TCLE) via e-mail; acordo de confidencialidade das informações fornecidas perante o grupo. Para a manutenção e o desenvolvimento das sessões focalizadas, fundamentamo-nos nas contribuições de Kind (2004), que pressupõe todo um processo que engloba: 1) introdução; 2) preparação; 3) conjunto do debate em grupo; 4) encerramento do grupo; 5) questões posteriores à avaliação do grupo; 6) ação posterior.

Enquanto instrumentos de coleta e geração de dados, além da técnica adotada, aplicamos um formulário de pesquisa on-line e utilizamos as notas do diário de campo do pesquisador. O formulário disponibilizado foi composto por 4 seções: apresentação, na qual informamos os aspectos éticos e convidamos os professores a participarem do grupo de discussões e da pesquisa; identificações gerais, que focalizou questões sobre os professores enquanto sujeitos sociais; formação e atuação acadêmico-profissional, na qual priorizamos assuntos sobre formação acadêmica e profissional, introduzindo duas questões sobre ensino remoto, questionando-os quanto à compreensão deste termo e se estão trabalhando remotamente; compreensões sobre currículo e orientações curriculares, por meio da qual focalizamos a compreensão conceitual do termo Currículo, do Projeto Político Pedagógico (PPP) e da Base Nacional Comum Curricular (BNCC).

Após convite e interesse dos participantes ${ }^{3}$ pelas discussões sobre essas temáticas, criamos um grupo no WhatsApp, disponibilizamos o formulário on-line e realizamos uma consulta sobre a disponibilidade de dias e horários, condições de acesso às plataformas on-line (familiaridade, internet etc.) e suas formas de interações (síncronas ou assíncronas). Conforme acordado, o grupo foi constituído por 10 participantes ${ }^{4}$ que optaram por um cronograma de reuniões semanais nas segundas-feiras, às 20 horas, realizadas através do Google Meet com interação síncrona.

\footnotetext{
${ }^{3} \mathrm{O}$ grupo foi constituído após convite realizado em live, na plataforma Instagram, pela Profa. Dra. Denise Lino de Araújo (UFCG), que foi entrevistada pela equipe do projeto Desengaveta Meu Texto, em parceria com a Revista Leia Escola, no dia 05 de maio de 2020.

${ }_{4}^{4}$ Além da participação do moderador (pesquisador), do observador (psicólogo convidado) e da supervisora (orientadora da pesquisa), o grupo foi constituído por 10 professores da Educação Básica, atuantes em instituições públicas e privadas de ensino. 9 são formados em Letras e 1 em Ciências Biológicas. Nesse grupo, 4 são especialistas, 3 são mestres e 3 são graduados.
} 
V. 11 (3)

233-254 set-dez 2021

No total, foram realizadas 8 sessões com durações de, aproximadamente, 1 hora e 15 minutos. Dada a natureza deste estudo e por explorarmos dados indiciários (GINZBURG, 1989) em processo de maturação, priorizamos como amostragem as respostas obtidas com o formulário on-line e as reflexões desenvolvidas na primeira sessão com os participantes PP1 e PP2 sobre a temática "ensino remoto". Optamos por essa sessão porque, como nos lembram Jodelet (2001) e Moscovici (2007), as representações possuem forte caráter do saber comum/popular e são evidenciadas em momentos de transição, como o propiciado pela sessão inaugural do grupo e pela nascente conceitual referente ao termo "ensino remoto".

A escolha para analisarmos os dados de PP1 e PP2 decorreu das suas singularidades. PP1 possui graduação em Letras - Língua Portuguesa e atua como professor de língua portuguesa há 7 anos em instituições privadas de ensino básico, nos níveis de Ensino Fundamental - Anos Finais e de Ensino Técnico com alunos do Ensino Médio. PP2 possui graduação em Ciências Biológicas, especialização em Tutoria para Licenciaturas Diversas a Distância e mestrado em Educação, atuando há 28 anos no ensino público no nível de Ensino Médio. Ao preencher o formulário on-line, esse professor também destacou que trabalhou durante 4 anos no curso de Biologia na modalidade a distância.

Com base no reconhecimento desses perfis acadêmicoprofissionais, acreditamos ser pertinente refletirmos a partir das contribuições desses participantes, em função da formação docente Letras e Ciências Biológicas, respectivamente -, do tempo de atuação - pleno e sênior - e do contexto que ocupam enquanto professores da Educação Básica - ensino privado e ensino público. Como forma de sistematizar informações sobre esses colaboradores selecionados, dispomos o quadro 1 abaixo:

Quadro 1 - Síntese sobre os participantes selecionados

\begin{tabular}{|c|c|c|c|c|c|}
\hline Identificação & Formação & Titulação & $\begin{array}{c}\text { Tempo de } \\
\text { atuação }\end{array}$ & $\begin{array}{c}\text { Local de } \\
\text { atuação }\end{array}$ & $\begin{array}{c}\text { Nível de } \\
\text { Ensino }\end{array}$ \\
\hline PP1 & $\begin{array}{c}\text { Letras - } \\
\text { Português }\end{array}$ & Graduado & 7 anos & $\begin{array}{c}\text { Instituições } \\
\text { Privadas }\end{array}$ & $\begin{array}{c}\text { Ensino } \\
\text { Fundamental } \\
\text { (Anos Finais) } \\
\text { e Ensino } \\
\text { Técnico }\end{array}$ \\
\hline PP2 & Biologia & $\begin{array}{c}\text { Pós- } \\
\text { graduado }\end{array}$ & 28 anos & $\begin{array}{c}\text { Instituições } \\
\text { Públicas }\end{array}$ & $\begin{array}{c}\text { Ensino } \\
\text { Médio }\end{array}$ \\
\hline
\end{tabular}

Fonte: Dados do formulário de pesquisa on-line (2021). 
Neste estudo, o corpus analisado é constituído pelas respostas às questões sobre ensino remoto do formulário de pesquisa on-line (identificadas como FP) e por excertos dos relatos (identificados como GD) desenvolvidos na sessão do grupo focal on-line. Do formulário, extraímos as respostas referentes às questões: i) O termo Ensino Remoto surgiu no Brasil no contexto da discussão sobre trabalho/ ensino durante a pandemia da COVID-19. Como você compreende esse termo?; ii) Em decorrência do contexto da COVID-19, você está atuando no ensino remoto? Na condição de professor, qual seu depoimento sobre a transição do ensino presencial para o ensino remoto?; da sessão focalizada, priorizamos o ponto norteador: i) Como vocês se veem e se avaliam neste período de transição das aulas? Os dados gerados foram transcritos através de uma adaptação das normas de transcrição de Marcuschi (1991).

Na seção seguinte, refletimos sobre as respostas extraídas dessas questões do formulário e dos excertos da participação dos professores eleitos na sessão focalizada. Os dados gerados foram analisados com base em duas categorias intimamente associadas e alinhadas aos fundamentos teórico-metodológicos deste estudo.

\section{Representações de professores sobre ensino remoto no cenário de transição das aulas presenciais às remotas on-line}

Os resultados discutidos nesta seção estão organizados a partir de duas categorias que emergem dos dados: a) representações profissionais espontâneas sobre ensino remoto; b) recepção sobre implantação do ensino remoto na transição das aulas presenciais às remotas on-line. É por meio da articulação dessas duas categorias que buscamos responder ao questionamento desta pesquisa, conforme veremos no desenvolvimento da presente análise.

a) representações profissionais espontâneas sobre ensino remoto

O processo integrante de "familiaridade" e "nãofamiliaridade" que constituem as representações dos professores sobre ensino remoto foi iniciado na solicitação de resposta ao formulário online, quando os questionamos sobre a compreensão deles quanto ao termo, o qual foi contextualizado a partir de seu surgimento no Brasil em função das medidas educacionais frente aos impactos da pandemia de COVID-19. Para melhor visualizarmos, seguem os excertos: 
V. 11 (3)

233-254 set-dez 2021

Excerto 01:

É um termo conhecido de maneira superficial devido a urgência do momento que vivemos. Acredito que as escolas e os professores tem se reinventado em uma situação emergencial (FP - PP1 sobre compreensão do termo "ensino remoto").

PP1 reconhece e compreende o ensino remoto como uma medida emergencial para guiar as ações no contexto pandêmico - [...] termo conhecido de maneira superficial devido a urgência do momento que vivemos. Conforme excerto 01, esse termo é representado sob a ótica profissional de (re)configurações do sistema escolar, especificamente por parte dos professores, dada a situação de crise, o que o qualifica enquanto uma representação contextualmente emergente. Essa representação parece estar em fase de assimilação no plano conceitual (JODELET, 2001) por parte de PP1, embora ele reflita sobre - [...] as escolas e os professores tem se reinventado [...].

Essa fase de assimilação da representação profissional sobre ensino remoto é evidenciada no excerto a seguir:

Excerto 02:

[...] outro sentimento que eu tive no início [....] eu tive a sensação de que eu estava planejando aulas 24 horas por dia né a sua mente ela não para porque você fica o tempo inteiro procurando ou pensando em coisas que você pode fazer pra tornar aquele ambiente ((a sala de aula virtual)) mais rentável possível aquele tempo mais proveitoso possível né então é esse misto de sentimentos que a gente tem sem contar a insegurança, sem contar com esse período de instabilidade né é um sentimento de instabilidade muito grande que a gente tem [...] mas com o tempo aquelas águas vão deixando de ser tão turvas né e vão ficando mais tranquilas né [...] (GD - PP1 sobre compreensão do ensino remoto).

No excerto 02, PP1 avalia que os processos de ensinoaprendizagem presenciais não devem ser transpostos sem quaisquer adequações para a modalidade virtual (FREIRE; LEFFA, 2013), pois a própria constituição do espaço e das interações desenvolvidas demandam ações e situações outras - [...] você fica o tempo inteiro procurando ou pensando em coisas que você pode fazer pra tornar aquele 
ambiente ((a sala de aula virtual)) mais rentável possível, aquele tempo mais proveitoso possivel. No seu relato, a representação sobre o ensino remoto surge enquanto uma alegoria à transição do estado de visualização da água - [...] com o tempo aquelas águas vão deixando de ser tão turvas né e vão ficando mais tranquilas [...] -, o que parece reafirmar a sua fase de assimilação/maturação de novas práticas do saber ser professor e dos novos conhecimentos profissionais demandados neste período de pandemia.

Essa fase inicial de constituição representacional também é compartilhada por PP2, conforme disposto no excerto 03:

Excerto 03:

No meu entendimento o ensino remoto é uma prática pontual (FP - PP2 sobre compreensão do termo "ensino remoto").

Compreender o ensino remoto enquanto uma prática pontual, conforme excerto 03, implica considerarmos que PP2 entende que as práticas pedagógicas desenvolvidas neste período acontecem apenas por conta da pandemia - [...] ensino remoto é uma prática pontual - e que não substituem a atuação docente desenvolvida anteriormente a esse contexto pandêmico. Essa visão é reiterada no excerto 04:

Excerto 04:

((avaliando sobre as medidas do Estado quanto à implantação do ensino remoto)) assim ô pra não ficar parado vamos trabalhar com educação remota o Estado basicamente começou assim [...] com relação à educação remota eu ainda não consegui compreender eu ainda não tô tendo essa compreensão por isso que eu quis participar do grupo de discussão [...] (GD PP2 sobre ensino remoto).

Ao enfatizar que ainda não compreendeu muito bem o termo - [...] com relação à educação remota eu ainda não consegui compreender [...] - do ponto de vista teórico-conceitual, conforme excerto 04, PP2 0 representa enquanto uma ação temporária para remediar as demandas do ensino presencial - [...] pra não ficar parado vamos trabalhar com educação remota o Estado basicamente começou assim [...]. No entanto, ao enfatizar que o Estado realizou a transição do ensino presencial ao remoto sem considerar algumas etapas, percebemos que, assim como $\mathrm{PP} 1, \mathrm{PP} 2$ compreende que o ensino na modalidade on-line requer toda uma formação para reconfiguração das práticas e ações docentes (FREIRE; 
V. 11 (3)

233-254

set-dez

2021
LEFFA, 2013). Essa forma de interligar a compreensão conceitual sobre ensino remoto ao seu processo de implantação nos leva à recepção que esses professores demonstraram ter durante as reflexões do formulário e da sessão focalizada, como veremos na seção a seguir.

b) recepção sobre implantação do ensino remoto na transição das aulas presenciais às remotas on-line

Ao se amalgamarem com experiências e sentimentos, as representações sociais e profissionais se tornam propulsoras para empreendermos processos de transição contextualmente situados. Neste caso, podemos inferir a recepção da implantação do ensino remoto pelas reflexões obtidas através das questões do formulário e dos relatos dos professores na sessão focalizada, considerando o cenário de transição das aulas presenciais às remotas on-line. Vejamos os excertos:

\section{Excerto 05:}

Tem sido um processo muito difícil de adaptação e conquista. Conquista dos professores tanto para com os alunos como também para com os pais. Por mais que eu ensine em instituições particulares não são todos os alunos que possuem estrutura e ambiente favorável para essa nova prática de ensino (FP - PP1 sobre transição do ensino presencial ao remoto).

Para PP1, conforme excerto 05, a transição das aulas é percebida enquanto um processo difícil, tendo em vista as suas implicações que demandam adaptação e conquista para esta nova realidade educacional. No entanto, há uma focalização nas condições de acesso e permanência ao ambiente virtual - [...] estrutura e ambiente favorável para essa nova prática de ensino -, o que implica associarmos sua recepção à perspectiva representacional contextual (BLIN, 1997), posta a problematização acerca do contexto que considera o vínculo entre instituição escolar, professor, alunos e pais/responsáveis - Conquista dos professores tanto para com os alunos como também para com os pais.

Essa dimensão representacional de ordem contextual, evidenciada na resposta de $\mathrm{PP} 1$, é reiterada com sua reflexão mediante ao grupo de discussões:

Excerto 06:

[...] sempre que você vai começar uma nova turma dá aquele friozinho na barriga legal né e:: eu costumo dizer aos 
meus colegas de trabalho que esse friozinho na barriga se espalhou agora pelo corpo inteiro né porque é uma novidade que chegou assim de repente e dentro da própria sala de aula a gente trabalha com conquista né o professor ele sempre tá conquistando o aluno né pra que a aula dele consiga fluir de maneira mais agradável [...] no ((nome da instituição)) nós entramos em quarentena dia 17 de março ((de 2020)) no dia 20 de março nós já começamos com as aulas remotas né pelo ((incompreensível)) a gente já teve que começar então a gente tem todo esse sentimento de conquistar o aluno fazer com que ele esteja ali naquele horário, naquele ambiente tratando-se da rede privada né é uma conquista que você faz tanto com o aluno como com os pais dos alunos né então esse sentimento de:: responsabilidade ele é ampliado pra o espaço familiar né porque os pais dos alunos estão ali muitos deles né ou alguns deles estão ali acompanhando suas aulas né então assim sua aula agora ela é pro mundo né [...] (GD - PP1 sobre transição do ensino presencial ao remoto).

A transição das aulas para PP1, conforme excerto 06, é representada simbólica e objetivamente (MOSCOVICI, 2007) como um calafrio que percorre o corpo inteiro do professor - [...] esse friozinho na barriga se espalhou agora pelo corpo inteiro [...] -, posta a maneira rápida de sua implantação no sistema escolar. A inquietação de PP1 para com os alunos, ou seja, a dimensão contextual da instituição escolar, reitera a sua preocupação demonstrada no excerto 05. Esse sentimento de preocupação é ampliado quando ele considera que sua aula deixa de ser vista de um ponto "privado", relação alunos-professor, e passa a ser experienciada também pelos pais/responsáveis - [...] os pais dos alunos estão ali muitos deles [...] acompanhando suas aulas [...]. Há certo alinhamento a uma representação imagética que atenta para uma ruptura de ordem identitária (BLIN, 1997), por meio da qual a representação sobre o ser professor é problematizada.

A transição das aulas sentida por PP1 indicia uma repercussão na sua representação sobre o sistema escolar, que aparenta centralizar alunos-professor em situação de sala de aula presencial, e parece ser reconfigurada/problematizada como uma decorrência da representação emergente sobre ensino remoto, a qual amplia a relação alunosprofessor em situação de sala de aula virtual, colocando-o em um espaço/ 
V. 11 (3)

233-254 set-dez 2021 entrelugar em que ele se visualiza "invadido" - [...] sua aula agora ela é pro mundo. De modo semelhante, PP2 corrobora com as compreensões de PP1 quando externaliza a sua percepção sobre o processo de transição, conforme excerto 07:

Excerto 07:

Da forma que foi realizado pelo governo [... foi um absurdo, sem uma consulta prévia, não foi realizado um levantamento de professores/alunos e material para compor o processo (FP - PP2 sobre transição do ensino presencial ao remoto).

No excerto 07, PP2 não avalia, propriamente, a transição das aulas, mas o processo desenvolvido por parte do governo. Podemos inferir que ela não se sente representada, enquanto profissional, pelas ações realizadas governamentalmente - [...] foi um absurdo, sem uma consulta prévia, não foi realizado um levantamento de professores/alunos e material para compor o processo - e, por isso, sua compreensão se assemelha a do participante PP1, quando enfatiza o contexto dos alunos. Essa reflexão é ampliada e aprofundada quando consideramos a participação de PP2 no grupo de discussões. Vejamos:

Excerto o8:

[...] eu queria deixar uma pequena reflexão, um questionamento, uma angústia [...] da forma que foi implementada a educação remota aqui na ((especificação do Estado)) tá ok? A ((nome da instituição)) [...] tá traçando um projeto pra trabalhar com educação remota mas eles estão fazendo um levantamento do corpo docente, do corpo discente, de toda a estrutura né através de questionário e reuniões, e no governo do estado da ((Estado)) ISSO NÃO ACONTECEU né [...] quase que imediatamente nós recebemos um link através das coordenações, das gestoras pra fazer uma formação que não teve nada com o contexto que estamos vivendo agora [...] pra ser feito em uma semana / entra faz tudo muito rápido, muito abrupto né [...] não começou com um diagnóstico do que que ele ((Estado)) tinha e o que ele iria fazer a partir do que ele tinha né [...] eu também sou dona de casa, sou professora, sou mãe e tudo mais então ou a gente organiza ou não dá certo [...] (GD - PP2 sobre transição do ensino presencial ao remoto). 
Antes de responder ao questionamento posto, conforme excerto 08, PP2 solicita o turno de fala para refletir sobre a implantação do ensino remoto, pois compreende que deveria ter havido um processo estruturado por etapas - levantamento, reuniões, consultas por questionários etc. - que considerasse não apenas o espaço e as condições (materiais, físicas, psicológicas) dos professores, mas também dos alunos - [...] no governo do estado da ((Estado)) ISSO NÃO ACONTECEU né. Por essa razão, ela percebeu a transição das aulas enquanto um processo muito rápido/abrupto - [...] entra faz tudo muito rápido, muito abrupto [...] -, do qual ela aparenta não se sentir representada.

Essa condição de não se sentir representada pela proposta do governo educacional, assim como PP1, parece ressaltar um sentimento de invasão decorrente das obrigações e ações profissionais em seu ambiente familiar - [...] eu também sou dona de casa, sou professora, sou mãe e tudo mais então ou a gente organiza ou não dá certo [...] -, visto a opacidade entre essas fronteiras no contexto de quarentena que impactaram diretamente na sua atuação e percepção como profissional.

Do ponto de vista recepcional, os relatos desses professores parecem evidenciar uma condição em que eles não se sentem representados pelas ações governamentais. Em face disso, sentem-se ansiosos, angustiados e incertos, tanto pelas demandas decorrentes do contexto pandêmico como pela forma de implantação do ensino remoto.

Alinhada a esse reconhecimento, a transição das aulas é vista como um processo de transição abrupto, rápido que parece desconsiderar a voz docente. Essa forma de recepcionar o processo de implantação do ensino remoto aparenta corroborar com as representações profissionais indiciadas sobre essa condição de ensino, que ainda está em fase de assimilação (JODELET, 2001) por parte desses professores.

\section{Considerações finais}

Investigar as crises que permeiam o ensino remoto, considerando o período de transição das aulas presenciais às remotas on-line, permitiu indiciarmos as percepções nascentes sobre o ofício do professor em contexto de distanciamento social. Para isso, partimos do questionamento - Que crises parecem se sobrepor nos relatos de professores em situação de pandemia? - e elegemos como objetivos: i) identificar representação(ões) de professores sobre ensino remoto em contexto 
V. 11 (3)

233-254

set-dez

2021

de distanciamento social; ii) verificar recepção de professores sobre a implantação do ensino remoto no cenário de transição do ensino presencial ao on-line.

Com base nesses objetivos, identificamos que os professores representam o ensino remoto como uma medida emergencial para minimizar os impactos da pandemia de COVID-19 no sistema educacional, embora ainda estejam no processo de maturação para ancorá-lo e objetivá-lo. No entanto, verificamos que a recepção da implantação do ensino remoto não ocorreu de forma pacífica, uma vez que foram surpreendidos pela transição das aulas.

Os professores avaliaram que as ações promovidas pelas entidades educacionais foram muito rápidas, abruptas - embora compreensíveis porque ninguém estava preparado para enfrentar e se (re) configurar perante a uma pandemia vivenciada globalmente - e que seria imprescindível uma consulta com professores, alunos e pais/responsáveis sobre as condições de cada um para continuação e adaptação das práticas educacionais. Essas condições não dizem apenas do ponto de vista de formação docente e/ou de suporte material e financeiro para manutenção das atividades profissionais, mas também de uma condição socioespacial de caráter psicológico, uma vez que os professores se qualificaram como ansiosos e angustiados durante as sessões focalizadas.

Orientados pelo questionamento de pesquisa, depreendemos que é nesse ponto que há uma crise que se sobrepõe nos relatos dos professores. Os dados parecem evidenciar uma ruptura na própria condição de atuação docente, a qual é impulsionada pela não consideração de uma voz docente coletiva no processo de implantação das ações remotas e pelo espaço ocupado pelos professores nessa conjuntura complexa. Sob esse último ponto, o ambiente antes familiar é "invadido" pelo espaço profissional, constituindo um espaço de desterritorialização/reterritorialização (DELEUZE; GUATTARI, 1992) e, ao mesmo tempo, um entrelugar, no qual as zonas limítrofes entre o ser familiar e o ser professor se aglutinam.

Por fim, avaliamos essas considerações finais como provisórias, em função da amostragem dos dados abordados neste trabalho. Entendemos que as categorias analíticas adotadas demandam ampliação e aprofundamento desses dados através da inserção da colaboração dos demais participantes do grupo focal on-line, com vistas à maturação das representações profissionais sobre ensino remoto indiciadas nesta pesquisa. 


\section{Referências}

ABDALLA, Maria F. B. Formação, profissionalidade e representações profissionais dos professores: concepções em jogo. Revista de Educação PUCCampinas, v. 22, n. 2, 2017, maio-agosto, p. 171-190.

ALVES, Roberta B. Entre a rodoviária e a prisão sem muros: sentidos e práticas sobre violência para profissionais de uma rede assistência. Tese (Doutorado em Psicologia) - Universidade Federal do Espírito Santo, Centro de Ciências Humanas e Naturais, 2016.

BLIN, J-F. Représentations, pratiques et identités profissionelles. Paris: L'Harmattan, 1997.

BORDINI, Gabriela S.; SPERB, Tania M. O uso dos grupos concentra-se em sincronização on-line em pesquisa qualitativa. Psicol. estud. Maringá, v. 16, n. 3, p. 437-445, set. 2011.

BORTONI-RICARDO, Stella M. O professor pesquisador: introdução à pesquisa qualitativa. São Paulo: Parábola Editorial, 2008.

BRASIL. Ministério da Educação. Base Nacional Comum Curricular. Brasília: MEC, 2017. Disponível em: http://basenacionalcomum.mec.gov.br/. Acesso em: 04 nov. 2020.

BRASIL. Ministério da Educação. Gabinete do Ministro. Portaria No 343, de 17 de março de 2020. Brasília, 2020.

DELEUZE, Gilles; GUATTARI, Félix. o que é a Filosofia?. Lisboa: Presença, 1992.

DIAS-TRINDADE, Sara; CORREIA, Joana D.; HENRIQUES, Susana. O ensino remoto emergencial na educação básica brasileira e portuguesa: a perspectiva dos docentes. Rev. Tempos Espaços Educ., v. 13, n. 32, jan./dez., 2020.

FREIRE, Maria M.; LEFFA, Vilson J. A auto-heteroecoformação tecnológica. In: MOITA LOPES, L. P. (org.). Linguística Aplicada na Modernidade Recente. São Paulo: Parábola, 2013. p. 59-78.

GAMA, Agleice M. O letramento digital e a escola como sua principal agência. Revista Memento, v. 3, n. 1, jan.-jul. 2012.

GINZBRUG, Carlo. Mitos, Emblemas e Sinais: morfologia e história. São Paulo: Cia das Letras, 1989.

GUARESCHI, Pedrinho A.; JOVCHELOVITCH, Sandra. Textos em representações sociais. Petrópolis, RJ: Vozes, 1995.

JODELET, Denise. Representações sociais: um domínio em expansão. In: JODELET, Denise (ed.). As representações sociais. Rio de Janeiro: UERJ, 2001. p. $17-44$.

KIND, Luciana. Notas para o trabalho com a técnica de grupos focais. Psicologia em Revista, Belo Horizonte, v. 10, n. 15, p. 124-136, jun. 2004. 
V. 11 (3)

$233-254$

set-dez 2021

KOZINETS, Robert V. Netnografia: Realizando pesquisa etnográfica online. Porto Alegre: Penso, 2014.

LARSEN-FREEMAN, Diane; CAMERON; Lynne. Complex systems and applied linguistics. Oxford: Oxford University Press, 2008.

LÉVY, Pierre. Cibercultura. São Paulo: Editora 34, 1999.

LINO DE ARAÚJO, Denise et al. Desengavetando a pandemia de 2020 à luz da educação: tem coisa que só o professor sabe explicar. Campina Grande: Editora Leve, 2020.

MARCUSCHI, Luiz A. Análise da conversação. São Paulo: Editora Ática, 1991.

MARTIN, Alain. Digital Literacy and the "digital society". In: LANKSHEAR, Colin; KNOBEL, Michele (ed.). Digital Literacies: Concepts, Policies and Practices. New York: Peter Lang Publishing, 2008. p. 151-176.

MILLER, Inés K. Formação de professores de línguas: da eficiência à reflexão crítica e ética. In: MOITA LOPES, Luiz Paulo da. (org.). Linguística aplicada na modernidade recente. São Paulo: Parábola, 2013. p. 99-121.

MOITA LOPES, Luiz Paulo da (org.). Por uma linguística aplicada indisciplinar. São Paulo, Parábola, 2006.

MOITA LOPES, Luiz Paulo da (org.). Linguística aplicada na modernidade recente. São Paulo: Parábola, 2013.

MOITA LOPES, Luiz Paulo da. Entrevista - Linguística Aplicada Indisciplinar. Grau Zero - Revista de Crítica Cultural, v. 3, n. 2, 2015.

MORIN, Edgar. Introdução ao pensamento complexo. Porto Alegre: Sulina, 1990.

MORIN, Edgar. Ciência com consciência. Rio de Janeiro: Bertrand Brasil, 2005.

MOSCOVICI, Serge. Representações sociais: investigações em psicologia social. Petrópolis: Editora Vozes, 2007.

MURRAY, Peter J. Using virtual focus groups in qualitative research. Qualitative Health Research, v. 7, n. 4, nov. 1997, p. 542-554.

ORGANIZAÇÃO MUNDIAL DE SAÚDE (OMS). Histórico da pandemia de COVID-19. Disponível em: https://www.paho.org/pt/covid19/historico-dapandemia-covid-19. Acesso em: 02 abr. 2021.

TARDIF, Maurice; LESSARD, Claude (org.). o ofício do professor: história, perspectivas e desafios internacionais. Petrópolis, RJ: Vozes, 2014.

XAVIER, Antônio C. Letramento digital e ensino. In: SANTOS, Carmi F.; MENDONÇA, Márcia (org.). Alfabetização e letramento: conceitos e relações. Belo Horizonte: Autêntica, 2005. p. 133-148. 